\title{
Explicating Abjection - Historically White Universities creating Natives of Nowhere?
}

\author{
Siseko H. Kumalo
}

Philosophy Department, University of Pretoria

(Received 7 April 2018; accepted 12 June 2018)

\begin{abstract}
In Ebrahim Patel's, The world of Nat Nakasa: A collection of letters, Nathaniel Nakasa's term 'Native of Nowhere' describes Nakasa's experience of leaving South Africa on an exit permit. Negotiating his classification as an aggressor of the state, Nakasa's expression signals his confrontation with his expendability as a Native in a country founded on the use of Blackness as Blackbodies that prop up white supremacy and rule. 'Native of Nowhere' here details how historically white universities in South Africa perpetuate ontological negations, through denying Blackness in institutions formerly reserved for whiteness. Through an analysis that implicitly posits education as a public good, I argue for the use of education as an emancipatory tool. Using Jean-Paul Sartre's Being and Nothingness to analyse negation, I develop the 'Native of Nowhere' to articulate a critical pedagogy, which delivers on the emancipatory potential of education.
\end{abstract}

\section{'Our country's strong, our country's young, and her greatest songs are still unsung,}

Keywords: abjection, education, emancipatory politics, native of nowhere, negation

'Dance, when you're broken open. Dance, if you've torn the bandage off. Dance in the middle of the fighting. Dance in your blood. Dance when you're perfectly free'.

$$
\text { -Rumi, (1207-1272) }
$$

Understanding the abjection ${ }^{2}$ of Blackness in the contemporary South African university, requires an analysis of institutional cultures and modes of being which confer citizenship and dictate Being and belonging in the university. I interrogate the dominant cultures in the

\footnotetext{
${ }^{1}$ Jansen, J.D. 2009. Knowledge in the Blood: Confronting race and the apartheid past. Pretoria: Juta and Company.

${ }^{2}$ Abjection as used in this argument is borrowed from the work of Kristeva (1982: 1) wherein she details how abjections is formulated as "the quality of being [which is] opposed to the "I"'. The abject as Kristeva details 'drives us to the place where meaning collapses, it is denotative [of that which is] ejected, discarded and jettisoned' (1982: 2). Its use in this argument subsequently foregrounds how the negation of Blackness is detailed, through modes of silencing and erasure which are attempted with perilous systematicity in Historically White Institutions.
}

Vol.6, No. 1 (2018): pp. 1-17

Corresponding author: jdd@up.ac.za

doi: 10.14426/cristal.v6i1.132 
academe as an entry point into my analysis which reveals the objective of this paper highlighting how the historically white university (HWUs) creates the 'Native of Nowhere' 3 through negations and erasures. The aim of exposition in the analysis is to showcase how HWUs can subvert injustices through a pedagogy of mutual (in)fallibility which intimates towards becoming fully human. I must be clear that the project of a pedagogy of mutual (in)fallibility is not only directed towards Blackness, rather it speaks to creating both of Blackness and whiteness, Beings that are fully human, for in the process of dehumanising the Other, the oppressor are themselves dehumanised. I do not defend a decolonial approach to the project of redefining the university, as I am more concerned with understanding how the Black/Indigenous Being becomes the Native of Nowhere, through modes of negation and erasure. While the project of tracing and revealing abjection will follow what seems like a decolonial approach, I remain suspicious and weary of decolonising strategies which are manifesting as another mode of coloniality in the contemporary academe, what we call (de)colonising strategies in our previous work (Almeida \& Kumalo, 2018). These (de)colonial strategies co-opt Blackness/Indigeneity into performances of decolonisation that commodify, consume and erase Blackness/Indigeneity in the academe.

To resolve the quagmire highlighted in this argument, I appeal to the concept of mutual (in)fallibility, which necessitates a revelation of my allegiances before I begin this project. Therefore, my first allegiance is to knowledge and educational desire, second is my discipline (philosophy), and thirdly, my Blackness and Indigeneity which constitutes the various manifestations of my Being ${ }^{4}$. Through revealing these implicit biases which I frame as my allegiances, my objective is to showcase how I, even as a Black/Indigenous body, can maintain systems of injustice, oppression, and domination. Revealing these biases curates a pedagogical space that allows the student in my lecture theatre, the reader of this text, and my peers who evaluate my work the capacity to see me as human, thus beckoning us to embark on a journey of learning wherein the end goal is intimation towards becoming fully human. The use of a pedagogy of mutual (in)fallibility resolves the quagmire of HWUs creating the

\footnotetext{
3 The concept of the 'Native of Nowhere' as used in the argument is useful for two reasons: firstly, it foregrounds how Black epistemologies and modes of being are relegated to the periphery in the contemporary Historically White University, leading to the second reason for its usefulness. Secondly, the concept showcases how Blackness is used to prop-up whiteness and ideologies of white supremacy which confer citizenship and belonging to settler colonial descendants, while relegating Indigeneity to the realm of the zone of non-being.

${ }^{4}$ The act of revealing my allegiances in the contemporary South African university allows me to acknowledge my limitations as a knower; limitations which privilege one position of analysis while silencing others. This position is developed in how the discipline of philosophy disciplines the subject to conform to disciplinary methodology. While a commitment to knowledge and educational desire seems on the surface worthy, implicated in this allegiance are my complicities in maintaining structures of power through defining the parameters of discourse in knowledge; who is a knower, and how we come to justify knowledge claims in the knowledge production economy (see Babbitt, 2017). Thus, the act of revealing my allegiances works to shoreup how we maintain systems of power, domination and oppression, which are elided by our commitments to specific socio-political agendas. The objectives of a pedagogy of mutual (in)fallibility works to reveal how the pedagogue, the professor, and the researcher are implicated in systems of power and domination, which is revealed when we begin to take seriously our variant allegiances and how they function in power relations. These power relations are most aptly demonstrated when interrogating how specific identity markers are privileged while neglecting the plethora of further identities which require substantive engagement in the contemporary university for the project of institutional transformation and substantive decolonisation.
} 
Native of Nowhere that I highlight in the paper through recognising the humanity of those who are classified as Other in the pedagogical space, thus effectively responding to the ethical injunction of fully becoming human which, as argued by Warnock (2012), denotes a comprehensive conception of freedom.

\section{Coloniality as Erasure and Negation}

Coloniality and the power relations inherent in the knowledge production economy manifest themselves glaringly in the South African context. Cudd (2006: 4) offers that oppression is a 'fundamental social injustice', involving tyranny and violence. In this argument, I concur with Cudd (2006) and suggest that there are fundamental epistemic injustices maintained in privileging a Eurocentric conception of knowledge in a post-apartheid, decolonial/decolonising South Africa. These injustices can be termed inherently abhorrent, for they not only commit testimonial but also hermeneutical injustices. Fricker (2007) is an apt point of entry into detailing the concepts of testimonial and hermeneutical injustice as witnessed in the South African context. 'Testimonial injustice' denotes how Blackness/Indigeneity is often denied credibility when raising concerns about the lack of decolonisation in the academe, while 'hermeneutical injustice' connotes structural injustice, which denies Blackness/Indigeneity the vocabulary with which to articulate its experiences and marginalisation in the academe. Through these modes of silencing, I maintain that Blackness/Indigeneity is continuously and strategically re-framed to serve the purposes of whiteness, thus, reaffirming the claim of abjection in the university.

In their argument Tuck and Yang (2012) demand that the land be returned, and whiteness render itself as the minority in the Canadian context, which echoes the sentiments of Nkosi (1989) who lamented the erasure of Indigenous/Black voices under apartheid in South Africa. Nkosi argues that the silencing of Indigenous/Black voices resulted in a reading of the landscape through misrecognitions and epistemic impositions. Through Tuck and Yang (2012) and Nkosi (1989) the interconnections between ontological frameworks and the epistemic paradigms we use to interpret and navigate our realities become clear. Continuing the tradition of privileging western epistemic frameworks through reading scholars which do not speak to the Indigenous/Black scholar, I maintain that the contemporary academe annihilates Indigeneity/Blackness through epistemic impositions. Sullivan (2006) argues that the erasures, consumptions, and commodifications of Indigeneity can be seen most vividly through an analysis of the European/(world) Wars, which sought to legitimate the plundering and pillaging of Oriental states and territories. Sullivan's (2006) work illustrates the habits of whiteness that are informed by colonial power dynamics, which define and frame Blackness as the abject Being from which to continuously take and draw. The continuous extraction from Blackness/Indigeneity is linked to the consumption and commodification of Blackness/Indigeneity which sees Blackness/Indigeneity invited into whitely spaces merely as a mode of legitimating claims of (de)colonisation.

\section{Ontological Recognition through the \#Fallist Movement}

To begin with, my interpretation of the contemporary student movement (\#MustFall) is framed by what I understand to be the contestation of visibilities. I conceptualise the contestation of visibilities as the desire to be recognised and the humanity of those framed as 
Other in the pedagogical journey to be seen as legitimate. The contestation of visibilities denotes the desire for ontological recognition, which is similar to the notion of educational desire used by Mirza (2006) in her argument wherein she considers the possibilities of the children of immigrants in the United Kingdom. To frame the contemporary university as a space which gives rise to the contestation of visibilities - specifically HWUs - is inspired by the work of Fanon (1952/2009) when he writes about The fact of blackness. Fanon (1952/2009: 257) argues,

[a]s long as the black man is among his own, he will have no occasion, except in minor internal conflicts, to experience his being through others. There is of course the moment of "being for others," of which Hegel speaks, but every ontology is made unattainable in a colonized and civilized society.

The ontologies of Blackness, specifically, are made unattainable owing to how they are framed as mythological and fictitious through the denial of Indigenous epistemic frameworks. This denial is envisaged in the continued imposition of colonial languages as a mode of instruction in the academe; however, I am not concerned with this debate here as I develop it elsewhere. Rather my objective lies in responding to the phenomenon of a Native of Nowhere, through the use of a pedagogy of mutual (in)fallibility.

Systems of education which negate the ontological dimension of Blackness/Indigeneity and deny it legitimate existence within the contemporary academe, substantiate Fanon's (1952/2009) claim that no ontology is attainable in a colonised and civilised society. I make the claim in this argument that the humanity of the oppressor (whiteness), is itself obfuscated owing to the modes of oppression, which dehumanise the oppressed and the oppressor. Through the inability to fully realise one's own humanity, in spaces which negate and deny one's Being and belonging, it becomes necessary to critically examine the emancipatory potentialities and resistance strategies available to the negated Being in re-asserting their humanity. What we have witnessed in responses that resist ontological re-framing that manifests as the creation of the Native of Nowhere in the contemporary university has been precisely the aim to assert the humanity of Blackness/Indigeneity in whitely spaces as it has been framed as Other; therefore, necessitating the decolonisation of the academe. It is on this premise that I claim that the actions of the student movement can be framed through the concept of a contestation of visibilities. As a mode of substantiating this position, I wish to consider the articulations of Frosh (2001) and Butler (1993).

Frosh (2006: 67), who writes from a psychoanalytical position, maintains that in order for citizenship and group identity to be conferred upon the individual, there ought to exist 'an Other that is feared even in the destruction' and killing of the said Other. The Other exists outside group identity and represents the basest desire which is curtailed by the mechanisms that confer group identity and belonging on the individual. Butler (1993: 38), on the other hand, systematically considers the 'Body that Matters' and argues that the 'feminised body has always been rejected by philosophy' in order for the tradition to constitute itself. It becomes essential that the self should repel the Other to constitute itself. Repelling the Other to constitute the self is envisaged in how the HWU creates the Native of Nowhere, through erasures that distinguish between the Being that belongs and the abject Other. 
Warnock (2012: xi) who introduces Sartre's Being and nothingness writes '[o]ne cannot understand the extent of human freedom unless one can understand what it is like to be a human being'. This assertion reveals that freedom can only be understood from a perspective that has fully been recognised as human, while implicitly suggesting that there are those who cannot understand freedom as they have not been embraced into the fold of humanity. Those who are not yet embraced into the fold of humanity are the Others who delimit between that which is human and that which abject. Understanding what it means to be human has two implications for this argument: the first signifies the backdrop against which the claim of abjection will be framed, while the second indicates the need to understand the role of education in facilitating the journey of becoming fully human.

\section{Eviscerating Pedagogies and Humanising Alternatives}

I have so far outlined the strategies of silencing, erasure, and abjection used in the academe. These strategies manifest through discourses that delimit between those that are human and those defined as Other; a definition rooted in the colonial project. Through delineating between those who are considered human and those who are not, the academe confers citizenship, belonging, and freedom while the Other is arrested in categories that reduce them to abject Beings. I, therefore, trace the root of these strategies of abjection through showcasing how historical trauma informs eviscerating pedagogies. Tracing this history will have as its objective the project of suggesting alternatives that are concerned with a humanising praxis in education.

To concern myself with the notion of fully becoming human requires that I briefly sketch the role of contested identities or what I term the contestation of visibilities in the South African context of Historically White Institutions (HWI). It has become apparent that Blackness is constantly rejected and negated in HWIs even in a democratic dispensation. I wish to turn to two incidents that took place at Maritzburg College and Pietermaritzburg Girls' High School in 2017. The incidents of white students, one in a senior leadership position and the other an aspiring leader in her context, suggests negation, through the use of the word 'Kaffir' ${ }^{5}$ to refer to fellow Black students. The racial slur was used at Maritzburg College by a Deputy Head Prefect in reference to one of his classmates, a fellow Black Prefect owing to a disagreement between the two boys; a matter to which I will return later. The incident at Pietermaritzburg Girls' High School arose from Black girls misplacing the accent in the spelling of their white peers' name. Outraged by how these Black girls butchered her name, this young white woman was heard on social media referring to her fellow colleagues as 'Kaffirs'. What I wish to highlight in these incidents is the postconflictual nature of South African society, which remains immersed in the residue of racial hatred and animosity. We further are invited to witness the offence taken by those who are defined as 'human' and their responses when met with disagreement between themselves and the Other. In accordance with the assertions of Arendt (1961: 11), the role of education becomes 'preserving the world against the mortality' of its creators, which denotes constantly setting the 'world right anew'. Setting the world right anew proclaims the responsibility of

\footnotetext{
${ }^{5}$ The term 'Kaffir' in the South African context represents a demeaning and dehumanising term which was used to refer to Black/Indigenous bodies during the apartheid era.
} 
confronting the racial animosity to create a generative pedagogical space. This injunction denotes correcting the perversions of the category of 'human'; perversions which are inherently linked to the project of colonialism/coloniality and apartheid. I concur with Arendt (1961: 10) that those 'who refuse to assume joint responsibility for the world should not' educate. This assertion is premised on how Blackness/Indigeneity continues to exist as expendable in these institutions, being chided for its response to the racial hatred, animosity, and ontic-ontological negation, which results in abjection.

This chastising response is witnessed at Maritzburg College when the Prefect involved in the 'Kaffir'-incident ${ }^{6}$ earlier in the year retaliated by branding his shirt 'EFF our last hope of getting our Land Back' at the end of the year. While the school responded with visceral disciplinary action that sought to remind Blackness/Indigeneity of its place in white institutions, the response given by the KwaZulu-Natal Department of Education highlighted how HWIs continue to see Blackness/Indigeneity as expendable and thus abject beings; therefore, negating the humanity of Blackness/Indigeneity. The abject Being exists outside of that which has been defined as fully human. That which is defined as human, specifically in the context of a post-conflictual society such as ours, is whiteness. Blackness exist as that which 'disturbs the identity' (Kristeva, 1989: 6) of whiteness and its attendant supremacist views which would have Blackness continuing to be relegated to the role of perpetual servant to the white master subsequently revealing the abject nature of Blackness/Indigeneity in HWIs.

This anecdotal exposition which centres the notion of Black/Indigenous abjection emphasises the precondition of the assimilation of Blackness/Indigeneity into whiteness if Blackness is to exist in spaces formerly reserved for whiteness, which results in the rejection of Blackness/Indigeneity by both the whiteness into which it is made to assimilate and its native identity which no longer recognises the assimilated being. This predisposition creates of Blackness/Indigeneity a Native of Nowhere through sustained negations both from whiteness and its native identity that no longer recognises the assimilated Being. The position to which Blackness/Indigeneity has been relegated supports the claim made by Quayson (2002), who maintains that we have been consigned to responding from a position, which we ought not to have been standing.

While the negation of Blackness/Indigeneity in spaces of teaching and learning has gone on in silence for most of the democratic dispensation in South Africa, this silence has been challenged through student activism which is reclaiming the legitimacy with which Blackness/Indigeneity speaks in HWIs. Arendt (1961) and Fanon (1963/2007) subsequently become central for this project, in suggesting the future of education in the country. The question with which we are confronted aims to discern the following: will the academe use an emancipatory conception of education as articulated by Arendt (1961), or will the contemporary struggle for ontological recognition blindly emulate the writing of Fanon (1963/2007) using violence to assert the place of Blackness in the academe? My objective in

\footnotetext{
${ }^{6}$ The 'Kaffir'-incident is the one cited above the argument, wherein the Deputy-Head Prefect called his fellow Black student a 'Kaffir' with his actions being treated a minor misdemeanour by the school authorities. When responding with a branded school shirt, the Black boy was charged with inciting racial animosities and was threatened with severe disciplinary action.
} 
this project is rooted in substantiating the validity of the former Arendtian position as opposed to the latter Fanonian violence. An Arendtian conception of education I maintain, will begin the project of redefining how we understand the emancipatory potential of education.

An Arendtian conception of the emancipatory potential of education creates the possibility to work towards Jansen's (2012) suggestion, which posits education as a tool to disrupt. Educating to disrupt does not connote the turmoil which we have ${ }^{7}$ witnessed in the past (the 2015/16 academic years), but rather involves disrupting the assumed positions and values which maintain systems of domination and oppression. Disrupting engrained assumptions begins by paradigmatically shifting our classifications of the \#MustFall movement as thuggery to an acknowledgement that what is being demanded by the contemporary student is ontological recognition. Ontological recognition connotes removing the barriers of entry established by HWUs through decades of oppression, injustice, and exploitation expressed in colonialism, apartheid, and contemporary coloniality.

The tensions witnessed in the protests of 2016 in Higher Education, with students divided along racial lines, indicates the dire need to recognise Black/Indigenous ontologies or await the implosion of the South African Higher Education sector in its entirety. The claim that the continued impositions that manifest through strategies of silencing, erasure, and negation will lead to the destruction of the academe is substantiated by how I conceptualise the contemporary student movements' actions as an attempt at asserting its ontological legitimacy in the academe. While my objective is in advancing an Arendtian conception of education, I cannot elide the realities which we witnessed in 2016, where violence - state and democratic - was used on our campuses. What can be deduced from the student protests is the rejection of the expected and authorised mimesis, through tokenistic inclusion and belonging within HWUs.

The recognition of Black/Indigenous ontology advanced here is intrinsically linked to a fundamental paradigm shift which ought to occur to foster epistemic justice in the contemporary academe. Epistemic justice denotes how we affirm the ontological positions of Black/Indigenous identity through systematic and rigorous engagement with the epistemic traditions of Blackness/Indigeneity. This systematic engagement should not be misconstrued to mean the commodification, erasure and negation of Blackness witnessed through additive approaches to curriculum reform/decolonisation, but rather suggests an immersion into the African Vocabulary as suggested by Nkosi (1989) and developed in my work (Kumalo, 2018). In the process of commodification, consumption and erasure of Indigenous/Black ontologies the contemporary South African Indigenous/Black scholar becomes a pariah because of her/his inability to navigate and belong to the South African landscape, owing to the demand that $\mathrm{s} /$ he assimilate into whiteness which ultimately rejects her/him, while alienating her/him from her/his native identity, subsequently creating the Native of Nowhere.

\footnotetext{
${ }^{7}$ I do, however, appreciate that it was this mode of resistance which has facilitated these projects i.e. this essay which works towards the aims of transforming the academe. I am, however, cautious from a position that speaks to maintaining a commitment to educational desire and attainment, of not creating of the contemporary university, a space that is marred by seeing first philosophy as political. By steering clear of the turmoil witnessed in the academe, I am rather suggesting that our contemporary conceptions of first philosophy remain in the domain of the ontological and epistemological.
} 
Alienation from one's native identity is premised on demands of assimilation into a landscape defined by western epistemic impositions derived from colonial domination and continued subjugation, which manifests as coloniality. This dilemma creates of the Indigenous/Black ontology an oscillating being which cannot situate itself in an historical account of the Indigeneity/Blackness it seeks to claim. The objective therefore, of educating from a position that is informed by the African Vocabulary is pedagogical instruction that is informed by the context thus undoing the phenomenon of creating Natives of Nowhere. Creating the Native of Nowhere is premised on purported objective institutional discourses that result in abjection and negation.

\section{Abjection and Negation}

I wish to briefly distinguish how the objective subject created by the university informs the subjective self, which is constituted through experiential knowledge in HWUs. Vincent's (2015: 34) Tell us a new story navigates the precarity of institutional cultures and the inherent power dynamics that constitute social reality, while revealing that 'subjectivities in the university are constituted discursively'. The discursive element, while necessary for constituting one's subjectivity nuances how the university creates the legitimate knower and the abject Being through discourses of deficiency that create the trite occidental/oriental binary. These pedagogical discourses ascribe citizenship and belonging while further delineating the abject Being through deficiency discursive strategies that elide the contentious point of epistemic imposition.

Bangani and Kapp (2005: 9-10) whose work traced identities in transformation and shifting conceptions of being at home among Black students at a South African university, revealed feelings of inauthenticity in the university owing to the alienating experience of being 'unhomed'. Notions of being unhomed are linked to epistemic impositions maintained by mimetic pedagogical praxes, described in Lebakeng, Phalane and Dalindjebo's (2006: 72) work as pedagogies transposed 'from London, Manchester and Hull'. Vincent (2015: p. 36) subsequently argues that we ought to fashion transformation strategies from the 'materiality of institutional cultures', which denotes an understanding of how these 'institutional cultures are experienced, lived and negotiated'. Vincent's (2015) approach is instructive as it reveals how the objective subject ${ }^{8}$ is created by the university through discourses of legitimate knowers and deficient abject Beings, that are unhomed and subsequently become the Natives of Nowhere.

Abjection in the South African context is rooted in the tumultuous history of colonialism and coloniality that manifests as modernity. Ramon Grosfoguel (2013), who writes about the structure of knowledge in westernised universities, highlights the epistemic injustices committed through the act of privileging western epistemic frameworks.

To clarify how HWUs continue to arrest Black/Indigenous epistemologies I look at strategies of control, surveillance and continued modes of silencing which perpetuate systematic oppression of the Indigenous/Black scholar. Morreira (2015:3), in a discussion that details practices of establishing a praxis which emulates a decolonial higher education

\footnotetext{
${ }^{8}$ The objective subject here denotes the subject which is derived using epistemically imposed discourses in the academe; the subject who becomes decontextualised as argued by Boughey and McKenna (2016).
} 
system in Southern Africa, notes that, 'it is perhaps unsurprising in such a context that black learners are often institutionally positioned as somehow deficient in that they lack [Eurocentric] cultural capital the institution demands'. Cultural capital in the institutional space requires that Blackness/Indigeneity be conversant with the mores and cultural values which dominate the HWU while denouncing its identity, otherwise termed as the process of being 'unhomed' by Bangani and Kapp (2005). While the promise of belonging implies citizenship -signifying the recognition of ones' humanity- the university continues to consume and commodify Blackness/Indigeneity through strategies of criminalisation and surveillance witnessed contemporarily across all HWUs in the country. Criminalisation and surveillance supports the claim that Blackness continues to be viewed with suspicion in white spaces due to the narrative that frames Blackness as a threat to whiteness (Yancy, 2008; Mills, 1997; Mashele, 2011). Systems of criminalisation and surveillance locate Indigeneity in the position of the constant Other in whitely spaces (hooks, 2009), a phenomenon evidenced in the securitisation of campuses and heavy police presence in HWUs across South Africa during the \#FeesMustFall (\#FMF) movement.

False inclusion framed as open access that masks strategies of exclusion through financial barriers frustrates Blackness/Indigeneity owing to the position to which its epistemic frameworks and ontological foundations are consigned. These moves of false inclusion - which are false on the premise that they include Blackness/Indigeneity through claims of open access which in fact deny Blackness/Indigeneity and its position in the university - negate Black/Indigenous epistemologies and ontologies substantiating the assertion that Blackness is invited into whitely spaces merely to authorise claims of decolonisation and transformation (Almeida, 2015). Modes of false inclusion premised on authorising claims of decolonisation acutely demonstrate the claim of commodification, consumption, and erasure in the academe.

An example to demonstrate: imagine a Black/Indigenous student from a rural school in the Eastern Cape of South Africa. Her admission into the intellectual community characterises her as deficient, because of an education system which was deprived of resources therefore depriving her of an adequate ${ }^{9}$ educational experience. What the institution fails to realise, however, is that the deficiencies with which it characterises its new entrant are inextricably linked to the institutions prestige which is derived from colonialism, apartheid and systematic oppression. Furthermore, Boughey and McKenna (2016) argue that in the discourses of deficiency, the university creates the decontextualised learner through glossing over what Popkewitz and Brennan (1993) term the social epistemology. The social epistemology in philosophy of education is constitutive of the social, political and economic factors that influence and shape educational desire and attainment.

\section{The Origins of Negation - Textual Applications ${ }^{10}$ of Sartre}

\footnotetext{
${ }^{9}$ It is necessary to problematize the concept of an adequate education, as this narrative upholds western epistemic traditions as the pinnacle of knowledge production and ways of knowing. The notion of an adequate education maintains that knowledge from alternative epistemic positions is deficient and lacking in epistemic merit within the university, therefore substantiating its continued exclusion from the university.

${ }^{10}$ I wish to state that the use of Sartre's Being and Nothingness serves the purpose of undergirding the theoretical proposition that I am advancing in this argument.
} 
Linking the deficiencies of the student and the institutional prestige of the university is premised on Sartre's (1943/2012: 32) argument, which maintains that to know that the Being has been modified there must exist a pre-modification conception of the Being. Sartre allows me here to examine the relationship between the historical structures which under-resourced specific communities while advancing the development of others, what Sartre (1943/2012: 32) calls modifying 'the distribution of masses of being'. I anticipate an objection from some philosophers to this argument as Sartre (1943/2012: 32) further posits that 'even this expression is improper, for to posit otherness there must be a witness who can retain the past in some manner and compare it to the present in the form of no longer'. However, I will respond to this objection by returning to Sartre who sets up the preconditions which allow the classification of destruction as destruction. The preconditions therefore are, a) a claim to have experienced the destruction only when we classify it as such b) a relation of man to being which signifies a transcendence c) that allows man to apprehend another Being as destructible (Sartre, 1943/212: 32).

Before proceeding further with my analysis, I wish to consider the limitations of negation; 'let anyone deny being whatever he wishes, he can not cause it not to be, thanks to the fact that he denies that it is this or that' (Sartre, 1943: 39). Responding to Hegel's assertion that '(Being and nothingness) are empty abstractions', Sartre (1943/2012: p39) contends '[i]n a word, we must recall against Hegel that being is and that nothingness is not'. The denial, which fails to recognise the ontology of Blackness/Indigeneity cannot cause the existent to cease, owing to the fact that we deny its humanity. 'Negation proper (we are told) is unthinkable; it could appear only on the level of an act of judgement by which I should establish a comparison between the result anticipated and the result obtained' (Sartre, 1943/2012: 30). To proceed with my analysis, the question posed by Sartre (1943/2012: 31) is of invaluable import: '[i]s negation the structure of the judicative proposition at the origin of nothingness? Or on the contrary is nothingness as the structure of the real, the origin and foundation of negation?'. I understand Sartre to be asking the question of whether negation can be classified first and foremost as resulting from a value judgment given, subsequently reducing that being to nothingness. Alternatively, is nothingness that which precedes negation?

The history of colonialism, apartheid, and coloniality are pertinent in detailing how Blackness/Indigeneity existed only as a Blackbody - an object in the service of colonial structures of power. Blackness/Indigeneity existing as a Blackbody in service of the colonial social apparatus responds to Sartre's question with the assertion that negation is the structure of the judicative proposition, which serves to create the conceptual nothingness. This assertion is premised on the existence of Blackness/Indigeneity as a Blackbody which circumvents a crucial precondition laid out above, which denotes the transcendental relation that allows man to apprehend the Being as destructible. In the failure to apprehend Blackness/Indigeneity as destructible, the Blackbody becomes the abject dispensable/expendable being that is commodified, consumed and erased in whitely spaces. Following from the assertion that Being cannot be caused to cease to exist, is the existence of the existent regardless of the value judgement which may seek to negate the said Being. The quagmire created here - specifically as we exist in a post-conflictual society - draws our attention to the essential need for pedagogies of mutual (in)fallibility, which allow for the 
cultivation of values rooted in humanness. This claim is premised on Sartre's (1943/2012: 35) thesis that '[n]egation thus, is a refusal to existence' and a value judgement which in the case of South Africa has been expressed in the refusal to acknowledge the existence of Blackness/Indigeneity through colonialisms/coloniality and apartheid.

As a way of foregrounding the concept of mutual (in)fallibility I wish to return to the example of the new entrant into the university. The new entrant, while having been denied an adequate education due to historical injustices which sought to arrest Blackness in systems of exploitation and subjugation, does not cause the Being to cease to exist, but rather reveals the dialectical nature of negation. The dialectics of negation are rooted in the modification of the Being, owing to systems of oppression, injustice and apartheid, which as argued by Sartre connotes the distribution of the masses of being. The dialectics of negation reveal the inextricable link between the entrant and institution by showcasing how systems of oppression and domination attempt to deny the existence of the existent through underresourcing the systems that undergird the humanity of the existent, subsequently necessitating the use of pedagogies of mutual (in)fallibility in post-conflictual societies.

An education deemed inadequate, while conveniently concealing how this inadequacy arose, reveals the significance of mutual (in)fallibility and draws on the dialectics of pedagogy as a means of working towards fully becoming human. While the disciplinary knowledge qualifies the entrant from an Eastern Cape rural school as deficient, acknowledging her experiential knowledge allows entry into the historical processes which facilitated modes of her attempted negation. Pedagogical approaches that locate, understand and use the experiential knowledge of this Being, who is classified as deficient, allow for the revelation of the complicities of the university to be acknowledged, thus beginning the work of educating with the intent of humanising. Acknowledging the complicities of the university takes the form of confronting how resources were historically modified to privilege certain groups while arresting the development of Others, who become the abject, deficient nonbeing. Focusing on the deficiencies discourse limits the pedagogical scope and leads to a manipulation and controlling of Indigenous Beings, thus supporting the notion that Blackness/Indigeneity exists in white spaces merely to legitimate claims of (de)colonisation.

A probable response on the matter of recognition in relation to the humanity of Blackness/Indigeneity in HWUs, requires that we critically ask whether the academe recognises the humanity of Blackness/Indigeneity in the first instance. This question addresses the earlier claim which locates the \#FMF movement, not as an economic debate, but more broadly as a charge for the ontological recognition of the position of Blackness/Indigeneity.

\section{Resisting Abjection and Negation}

In Black Orpheus, Sartre (1965: 23) writes,

it is through this language alone that they can communicate; like the sixteenthcentury scholars who understood each other only in Latin, black [wo]men can meet only on that trap-covered ground that the white man has prepared for them: the colonist has arranged to be the eternal mediator between the colonized; he is therealways there - even when he is absent, even in the most secret meetings. And since words are ideas, when the negro declares in French that he rejects French culture, he 
accepts with one hand what he rejects with the other; he sets up the enemy's thinkingapparatus in himself, like a crusher (emphasis added).

Through co-option strategies which require that Blackness denounce its identity and assimilate into whiteness, the creation of the Native of Nowhere becomes apparent. These modes of ontological re-framing allow us to witness the systematic modes of abjection which aim at negation. As per the abovementioned, however, negation can never truly be achieved as it denies the existence of the existent, which is impossible as being is that which is, regardless of the value judgements one passes toward the existent.

It is in the act of ontological re-framing that I am pressed to consider Sartre's theses of the origins of negation. Sartre (1943/2012: 29) writes:

One will perhaps be tempted not to believe in the objective existence of a non-being; one will say that in this case the fact simply refers me to my subjectivity; I would learn from the transcendent being that the conduct sought is a pure fiction... "To be pure fiction" is equivalent here to "to be only a fiction". Consequently, to destroy the reality of the negation is to cause the reality of the reply to disappear. This reply, in fact is the very being which gives it to me; that reveals the negation to me.

In order to properly consider these theses in the context of this argument, it is perhaps useful to contextualise them in the preliminary assertions which Sartre develops to arrive at this conclusion. To establish the origin of the negation of the Being, Sartre (1943/2012: 28) argues that there exists a questioner and the questioned; the Being. From the question asked the questioner expects a reply that will reveal the Being and its ways of being. To question the Being about its ways of being and its Being, reveals the transcendental relation between man and the Being, therefore, allowing man to apprehend the Being as destructible (Sartre, 1943/2012: 28). From the question "[t]he reply will be a "yes" or a "no" (Sartre, 1943/2012: 28). 'It is the existence of these two equally objective and contradictory possibilities which on principle distinguishes the question from affirmation or negation' (Sartre, 1943/2012: 29). I understand Sartre (1943/2012) to be dealing with [wo]mans' relationality to the world, which reveals two objective realities by way of positing a reply that can either be a 'yes' or a 'no'. Furthermore, Sartre's theses reveal that negation is a response imbued with a value judgement. Negation, according to Sartre (1943/2012: 30), reveals 'the quality of judgement', proffered as a response to the question asked by the questioner. The quality of judgement thesis substantiates the claim that negation is a value judgement, which cannot cause the being to cease to exist, even as it may attempt to do so.

The institutional response which aims at refuting claims of abjection and negation refers the Being to its subjectivity, therefore, invalidating these claims on the basis of objective knowledge. Objective knowledge dismisses the Being through classifying experiential knowledge as illegitimate in the academe. The second strategy which is used here is to reduce the claim of negation to a fictional one and as Sartre (1943/2012: 29) maintains, '[t]o be pure fiction is equivalent here to, to be only a fiction' which causes the reply to disappear. At the disappearance of the reply the charge of negation can no longer stand as it is not rooted in any objective truth or empirical knowledge, which is the only mode of knowledge that the university recognises as legitimate. In prizing objective knowledge and negating the position of the Being, I claim that the university negates the Being; therefore, creating the Native of Nowhere. These moves make very clear how the 'structure of 
knowledge in the westernised university' (Grosfoguel, 2013) is rooted in colonial systems of power and domination, which allow the university to maintain legitimacy even as it refutes the lived realities of Blackness/Indigeneity.

Having detailed the modes of erasure, negation and consumption which are premised on coloniality, it is necessary to posit a suggestion, which begins to remedy this phenomenon. I argue for the use of a pedagogy of mutual (in)fallibility as a mode of advancing the remedying of continued negation and abjection in the academe.

\section{Mutual (In)fallibility as an emancipatory Pedagogical Tool}

The concept of mutual (in)fallibility is refracted from 'mutual vulnerability', which is developed by Keet, Zinn and Porteus (2009) for post-conflictual societies. The refraction acknowledges the ethical obligation of the pedagogue; balancing the prerequisite need to reveal injustice, while curating the pedagogical space in ways that do not impinge on teaching and learning. To frame the concept as mutual (in)fallibility is premised on the need to educate to disrupt as argued by Jansen (2009) without being confrontational and antagonistic to the student. (In)fallibility is derived from how the ingrained assumptions we hold (which we ought to disrupt through teaching and learning) seem, at first glance, infallible and incontestable.

Locating their discussion in the South African context, Keet, Zinn and Porteus (2009) point us to the need to establish a pedagogical space in which the historical traumas of society are used to advance teaching methodologies which not only respond to these historical traumas but are further used to ensure that the pedagogical environment is one which inspires the students to question their assumptions about those who are framed as Other. Mutual (in)fallibility therefore requires responses to social ills using creative teaching methodologies, similar to Jansen's (2009) notion of teaching to disrupt.

Zondi (2017) writing about dance as a pedagogical tool asks a critical question which contextualises the project of teaching with the intention of disrupting engrained assumptions. Zondi (2017: 5-46) asks, '[h]ow does black dance as a critical posture intend to move us, touch us, (dis)orient us, throw our assumptions into crisis, attend to the dead, reveal to us our complicities, and help us to seriously consider whether this is the kind of world worth saving?'. Zondi's (2017) work nuances and contextualises the concept of mutual (in)fallibility, which frames these precise questions for the purposes of advancing the objective of ontological recognition and challenging the socially established ideas about those framed as the Other. In a consideration of Tending toward Blackness, Copeland (2016) problematises the notion of limiting the thinking of the Other to their body, an assertion which underscores the need to expand our praxis in a pedagogy of mutual (in)fallibility to include the experiential knowledge brought into the pedagogical space by those framed as Other. Bringing this knowledge into the pedagogical space ungirds rigorous engagement with the notion of a 'world worth saving' (Zondi, 2017: 46), which can only be conceptualised through a pedagogy of (in)fallibility. Reading Copeland (2016) proper, requires that we acknowledge his request of heeding the political ontology of race and the importance of Blackness in and of itself, so as to unlock the emancipatory potential that lies in education. Unlocking the emancipatory potential of education through centring the political ontology of

Blackness denotes uncovering and confronting the historical traumas of 
colonialism/coloniality and apartheid, while using these traumas as a generative tool that intimates towards the objective of realising one's own humanity and seeing the humanity of the Other. This assertion comes from the knowledge that how we engage the world, not only determines what we know, but further gives rise to what can be classified as that which 'is said to be' (Copeland, 2016: 143-144).

Through positing the educational journey as a mode of responding to the challenges which plague post-conflictual societies like South Africa, by revealing the humanity of the Other, we are confronted with the question of abjection and negation specifically when we recognise education as a humanising tool. Framing education as a humanising tool has proven to have significant implications for this argument, in light of the claim that HWUs create the Native of Nowhere. The abjection of Blackness/Indigeneity which creates the Native of Nowhere rests on the acts of decolonising the university that do little to recognise the ontological position of Blackness/Indigeneity within the academe. While HWUs claim to be decolonising, acts of decolonisation are not supported by active inclusion and the recognition of the epistemic value of non-European/Anglo-American epistemic frameworks. Thus, inclusion in HWUs becomes an act of tokenism. This experience of tokenism compounds the oscillation of Blackness/Indigeneity which is denied existence in the academe while its reality, truth and knowledge are questioned outside the academe.

The oscillation experienced by Blackness/Indigeneity through systems of epistemic negation is framed by bell hooks (2009), a critical black feminist theorist, in her book Belonging: a culture of place as emanating from the discourse of colour blindness. Challenging colour blindness which obfuscates a genuine confrontation of historical trauma, hooks (2009) notes how these strategies necessitate that Blackness assimilate to whiteness. Colour blindness in South African historically white pedagogical spaces is the cornerstone that denies the educational experience the opportunity to use difference as a means of learning and a source of infusing the pedagogical process with diversity. This denial, which manifests through the modes of teaching and learning used in the whitely classroom, militates against the existence of Blackness/Indigeneity, necessitating assimilation which can otherwise be understood as oppression and as hooks (2009: p. 90) suggests may lead to a sense of 'self-loathing amongst Blackness'. Self-loathing further substantiates the claim that HWUs create the Native of Nowhere as these institutions frame the place of Blackness/Indigeneity and its belonging or lack thereof within whitely institutions. In the feeling of self-loathing within the HWU, I wish to conceptually remind my reader of the notion of being unhomed used in Bangani and Kapps's (2005) work. The notion of being unhomed is linked to self-loathing through an oscillation between assimilation into white spaces and the demand that Blackness/Indigeneity denounce its Indigenous identity which subsequently creates the Native of Nowhere. Self-loathing originates in the discourse that devalues Black/Indigenous ontologies through markers that classify these ontologies and epistemologies as deficient and thus lacking any epistemic merit in the university.

\section{Conclusion}

Forced assimilation within the pedagogical space showcases the concept of epistemic injustice, as violent modes of repression are used to discipline dissent from the customs which govern the educational experience within HWUs. Forced assimilation further 
underscores how the HWU creates the Native of Nowhere, through epistemic impositions, ontological erasures and negations which are premised on the consumption of Blackness/Indigeneity. What I have undertaken to prove in this paper is the claim that what we bear witness to in the contemporary student movement, that contests modes of erasure and negation, is a bid to assert the ontological foundations and legitimacies of Blackness/Indigeneity in the academe.

The demand that HWUs recognise the ontological legitimacy and epistemic contributions of Blackness/Indigeneity is premised on a pedagogy of mutual (in)fallibility that inspires the recognition of the humanity of the Other, thus practically realising the objective of social transformation and redress of South African society through Higher Education. MacIntyre ${ }^{11}$ (1973: 8) claims that what 'constitutes inclusion and exclusion from the educational processes' will be determined by how the contesting claims define an educational experience. Contesting what constitutes an educational experience is signified in the actions of students - over the course of 2015/2016 - who have questioned mimetic pedagogical strategies that devalue the epistemic contributions of Blackness/Indigeneity in the academe. The claim that these actions are a contestation of what constitutes the educational experience is evinced through the actions of students which must be read not merely as an economic struggle, but rather as the desire to assert the ontological and epistemic positions of those who have been relegated to the periphery in the academe; the Other.

Implicit in MacIntyre's (1973) assertion is the notion of a differential educational experience which is premised on differential ontological underpinnings. MacIntyre's (1973) argument showcases how epistemic injustice can be maintained - however implicit and nonintended - as counter ontological assertions are expelled on the basis that they do not fit the prerequisite standards outlined by the institutional culture of HWUs.

As a response to this quagmire, I propose the use of a pedagogy of mutual (in)fallibility as a humanising tool which frames education as a means by which we can begin to realise the humanity of the self and the Other. Acknowledging the humanity of the Other reframes the pedagogical journey to be a process that reveals our complicity in systems of domination and oppression, through an acknowledgement of our positionality in society; specifically, post-conflictual society. Using divergent/counter-hegemonic epistemic frameworks, which can only be achieved through mutual (in)fallibility in the project of teaching, learning and research - what I understand to be the bedrock of any higher education institution - the pedagogical space can begin to discharge its obligation as an emancipatory tool/institution in society.

Siseko H. Kumalo is Editor-in-Chief of the Journal of Decolonising Disciplines, a journal dedicated to decolonising disciplinary knowledge across faculties in higher education. His research focuses on epistemic justice, pedagogies of mutual (in)fallibility, feminist and queer

\footnotetext{
11 'Moreover, such rival understandings will entail not merely decisions to include or to exclude but decisions as to what are to count as central cases and what as marginal, and our treatment of prima facie counterexamples is necessarily affected by this allocation'.
} 
theory, violence, Education for Sustainable Development and higher education transformation. He is Lead Researcher of \#ThinkingAfrica under the Unsettling Paradigms Project (http://www.up.ac.za/unsettlingparadigms), which is an inter-institutional project coordinated by the University of Pretoria. He sits on the Executive Committee of the Philosophical Society of Southern Africa and is a Mandela Rhodes Foundation Scholar (2017).

\section{References:}

Almeida, S. \& Kumalo, S.H. 2018. (De)Coloniality through indigeneity: Deconstructing calls to decolonise in the South African and Canadian contexts. Education as Change, 22 (1), 1-24

Almeida, S. 2016. Four: Race-based epistemologies: The role of race and dominance in knowledge production, Wagadu: a Journal of Transnational Women's and Gender Studies, 13: 79-105.

Arendt, H. 1961. The crisis in education. Between Past and Future, 173-196.

Babbitt, S.E. 2017. Epistemic and Political Freedom. In Kidd, I.J., Medina, J and Pohlhaus Jr., G. (eds.) The Routledge Handbook on Epistemic Injustice. London and New York: Routledge Publishers.

Bangani, B \& Kapp, R. 2005. Identities in transition: Shifting conceptions of home among "black" South African university students. African Studies Review, 48(3): 1-19.

Boughey, C. \& McKenna, S. 2016. Academic literacy and the decontextualised learner. Critical Studies in Teaching and Learning, 4(2): 1-9.

Butler, J. 1993. The Body that matters: On the discursive limits of "sex". London and New York: Routledge Publishers.

Copeland, H. 2016. Tending-toward-Blackness. October, 156: 141-144.

Cudd, A. 2006. Analysing oppression. Oxford and New York: Oxford University Press.

Fanon, F. 2009 [1952]. The Fact of Blackness. In Back, L. \& Solomons, J. (eds.) Theories of race and racism: a reader. London and New York: Routledge Publishers, 257-266.

Fanon, F. 2007 [1963]. The wretched of the earth. New York: Grove Press

Fricker, M. (2007) Epistemic injustice: Power and the ethics of knowing. Oxford: Oxford University Press.

Frosh, S. 2001. Psychoanalysis, identity and citizenship. In Stevenson, N. (ed.). Culture and Citizenship. London: Sage Publications, 62-73.

Grosfoguel, R. 2013. The structure of knowledge in westernized universities: Epistemic $\mathrm{racism} / \mathrm{sexism}$ and the four genocides/epistemicides of the long 16th century. Human architecture, 11(1): 73-90.

hooks, b. 2009. Belonging: a culture of place. New York and London: Routledge Publishers.

Jansen, J.D. 2009. Knowledge in the blood: Confronting race and the apartheid past. Johannesburg, Juta and Company Ltd.

Lebakeng, T.J., Phalane, M.M. \& Dalindjebo, N. 2006. Epistemicide, institutional cultures and imperative for the Africanisation of universities in South Africa. Alternation, 13(1): $70-87$. 
Keet, A., Zinn, D., \& Porteus, K. 2009. Mutual vulnerability: A key principle in a humanising pedagogy in post-conflict societies. Perspectives in Education, 27(2): 109-119.

Kristeva, J. 1982. Powers of horror: An essay on abjection. New York, Columbia University Press.

Kumalo, S.H. 2018. Defining an African vocabulary: Culture, power and the complexity of identity, Alternation - Forthcoming

MacIntyre, A. C. 1988. Whose justice? Which rationality?. London, Duckworth.

Mashele, P. 2011. The death of our society. Johannesburg, CPR Press

Mills, C.W. 1997. The racial contract. Ithaca and London, Cornell University Press.

Mirza, H.S. 2006. 'Race', gender and educational desire. Race Ethnicity and Education, 9(2): $137-158$.

Morreira, S. 2017. Steps towards decolonial higher education in southern Africa? Epistemic disobedience in the Humanities. Journal of Asian and African Studies, 52(3): 287-308.

Nkosi, L. 1989. Review: White writing. Third World Quarterly, 11(1): 157-161.

Patel, E. 1997. The world of Nat Nakasa: A collection of letters. Johannesburg, Ravan Press.

Popkewitz, T.S. \& Brennan, M. 1998. Foucault's challenge discourse, knowledge, and power in education. New York, Columbia University Press.

Quayson, A. 2002. Obverse Denomination: Africa?. Public Culture, 14(3): 585-588.

Sartre, J-P. 1965. Black Orpheus. The Massachusetts Review, Inc., 6(1): 13-52.

Sartre, J-P. 2012 [1943]. Being and nothingness. London and New York, Routledge Publishers.

Sullivan, S. 2006. Revealing whiteness: The unconscious habits of racial privilege. Bloomington and Indianapolis, Indiana University Press.

Tuck, E. \& Yang, K.W. 2012. Decolonization is not a metaphor. Decolonization: Indigeneity, education \& society, 1(1): 1-40.

Vincent, L.D. 2015. Tell Us a New Story. In Tabensky, P. \& Matthews, S. (eds.) Being at home: Race, institutional culture and transformation at South African higher education institutions. Pietermaritzburg: University of KwaZulu-Natal Press, 21-44.

Yancy, G. 2008. Black bodies, white gazes: The continuing significance of race. New York and Toronto, Rowman and Littlefield Publishers.

Zondi, M. 2017. Memories of blood: To brother(hood) dance and all black movers. Propter Nos, 1(1): 45-52.

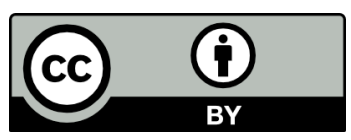

This publication is covered by a Creative Commons Attribution 4.0 International license. For further information please see: http://creativecommons.org/licenses/by/4.0/. 